\title{
A computed-based model for the alkali concentrations in pore solution of hydrating Portland cement paste
}

\author{
W. Chen \& Z.H. Shui \\ School of Materials Science and Engineering, Wuhan University of Technology, Wuhan, China \\ H.J.H. Brouwers \\ Department of Civil Engineering, University of Twente, Enschede, Netherlands
}

\begin{abstract}
A computed-based model for the alkali concentrations in pore solution of hydrating Portland cement paste is proposed. Experimental data reported in different literatures with thirteen different recipes are analyzed. A 3-D computer-based cement hydration model CEMHYD3D is used to simulate the hydration of these pastes. The models predictions are used as inputs for the alkali partition theory, which is used to derive the alkali binding capacity of C-S-H in hydrating Portland cement paste. A linear relation between the amount of boundalkali $\mathrm{Na}^{+}$in C-S-H and its concentration in the pore solution is found, whilst a non-linear relation should be employed for the amount of bound-alkali $\mathrm{K}^{+}$in C-S-H. New methods for predicting the alkali concentrations in the pore solution of hydrating Portland cement pastes are proposed based on the computer model CEMHYD3D, which is also validated with experimental results.
\end{abstract}

\section{INTRODUCTION}

The cement hydration process can essentially be considered as the interactions between the solid compounds and the liquid phase in the paste. The liquid phase contains some ions and is therefore called "pore solution". The pore solution normally contains ions like $\mathrm{OH}^{-}, \mathrm{K}^{+}, \mathrm{Na}^{+}, \mathrm{Ca}^{2+}, \mathrm{SO}_{4}^{2-}, \mathrm{Al}(\mathrm{OH})_{4}^{-}, \mathrm{H}_{3} \mathrm{SO}_{4}^{-}$, etc. with the alkali ions $\left(\mathrm{K}^{+}\right.$and $\left.\mathrm{Na}^{+}\right)$and $\mathrm{OH}^{-}$being the most dominant ones. The hydroxyl concentration in the pore solution of concrete is important due to its dominant effect on the likelihood of alkali-silica reaction (ASR) in concrete, the hydration of cement mixture containing contaminants for immobilization and stabilization (Van Eijk, 2001), stabilization of the oxide film on the surface of steel bar inhibiting further corrosion and the reactivity of some supplementary materials (slag, fly ash, etc.) in concrete.

The hydroxyl concentration is mainly controlled by the alkali concentrations in the pore solution, because the alkali ions are the most abundant cations in the solution and the hydroxyl ion is generated to maintain the charge neutrality.

Number of research on the alkali concentrations in the pore solution of hardening cement paste and concrete has been rising rapidly in the past decades. Most of the research is focused on the development of the alkali concentrations in the pore solution with the aids of experimental design. Effects of different factors on the alkali concentrations are investigated, like the use of supplementary materials (Diamond, 1981; Longuet, 1976), addition of mineral salt (Page \& Vennesland, 1983; Schäfer \& Meng, 2001), alkalinity of cement (Dehwah et al., 2002) and carbonation of concrete (Anstice et al., 2004). Most of the analysis is based on the pore solution compression method firstly introduced by Longuet et al. (1973).

Methods for predicting the alkali concentrations in the pore solution of hydrating cement paste are useful, although experimental setup is widely used to investigate the pore solution composition in hydrating cement paste. First, it takes lots of efforts to measure the alkali concentrations in mature concrete. Special care should be taken to minimize the environmental effect (Glasser, 2003). Second, the experiments cannot obtain quick results because no reliable methods are available to accelerate the hardening process of cement, the principal binder in concrete (Taylor, 1987). Third, the different factors can hardly be considered in a single batch of experiments. A large set of experiments need to be carried out to clarify the effect of each factor. Therefore, models for the pore solution composition can on one hand help to design the experimental scheme, and on the other hand predict the effect of various factors without the need of carrying out the time-consuming and costly experiments. 
In this study, a new computer-based model is proposed for the alkali concentrations in the pore solution of hydrating Portland cement. They are based on the methods developed by Taylor (1987) and Brouwers \& Van Eijk (2003), and a large set of experimental data taken from literature. The alkali-binding capacity of the hydration product C-S-H is determined with the theories and experimental data. Two binding models are proposed for $\mathrm{Na}^{+}$and $\mathrm{K}^{+}$, respectively.

\section{MODELS FOR ALKALI CONCENTRATIONS IN PORE SOLUTION}

\subsection{Pore solution composition}

The evolution of pore solution composition is firstly discussed. Immediately after mixing with water, remarkable amounts of alkali ions are released into the water, together with sulfate ions. After about 6 hours, the sulfate concentration starts to decline, accompanied by a rapid increase of the hydroxyl concentration. The drop of the sulfate ion is most likely caused by the formation of ettringite, which is proven by the rapid drop of aluminum in the pore solution. The alkali concentrations increase steadily during the first 24 hours, and keep increasing to maxima at about one week. Then, they start to decline and reach constant values. The calcium concentration remains always very low, although it is relatively higher in the first 20 hours than that in the later ages. The hydroxyl concentration in the pore solution is very low in the early ages, and it remains almost constant as long as sulfate presents in a large amount in the pore solution. Immediately after the sulfate ion becomes depleted, the hydroxyl concentration is increased greatly. The overall trend for the change of hydroxyl concentration is very similar to those of the alkali ions. The aluminum and silicon concentrations in the pore solution remain very low throughout the whole hydration process, less than $0.5 \mathrm{mmol} / \mathrm{L}$

Alkali salts are normally very soluble, i.e. they have high solubility in water; hence, considering the situation in the pore solution of hydrating cement paste, equilibrium between the solid compounds of alkali salts and the pore solution can hardly be established. Thus, the alkali ions are always dissolved into the solution when they are available. Therefore, their concentrations are determined by the amount of available alkalis and the volume of pore solution. For predicting the alkali concentrations, the methods proposed by Taylor (1987) and further developed by Brouwers \& Van Eijk (2003) are first introduced.

\subsection{Taylor's method}

Taylor (1987) proposed a method for predicting alkali ion concentrations in the pore solution of hydrated cement paste from more than one day old. The method takes use of the total contents of $\mathrm{Na}_{2} \mathrm{O}$ and $\mathrm{K}_{2} \mathrm{O}$ in the components and the water available for the pore solution. The alkali ions are partitioned between the pore solution and the hydration products.

The amount of alkali ions taken up by the hydration products is assumed proportional to its concentration in the solution and the amount of products as adsorbent. The concentration of ions in the solution is calculated from the remaining amount of alkali ions and the volume of solution. An empirical constant, namely the binding factor, is defined and derived both for $\mathrm{Na}^{+}$and $\mathrm{K}^{+}$. In the computations, the amounts of alkali ions released by the cement hydration and the hydration products are estimated using some empirical equations. The volume of pore solution is computed from the total water content in the paste and that combined in the products. The detailed procedure for predicting the alkali concentrations is as following.

The alkali oxides in cement are divided into two groups according to their state, namely "soluble" and "insoluble" alkalis. Pollitt \& Brown (1968) found part of alkali oxides in cement present as sulfate, which is instantly soluble after contact with water. The proportion of this part of alkali oxide depends on the sulfate content of cement. A detailed routine for computing this proportion is given by Taylor (1990). The rest of the alkali oxide is often found in solid solution in the alite, belite, aluminate and ferrite. It is released into the pore solution simultaneously as the hydration proceeds. Both these two parts of alkali oxides are available for the pore solution. The amount of alkali ions $\left(\mathrm{Na}^{+}\right.$or $\left.\mathrm{K}^{+}\right)$in the cement can be computed as:

$n_{i}^{T}=\frac{2 x_{i}}{M_{i}} \cdot m^{p}$

where $n_{i}^{T}=$ the moles of alkali ion $i\left(\mathrm{~K}^{+}\right.$or $\left.\mathrm{Na}^{+}\right)$in the cement; $n_{i}=$ the mass fraction of alkali oxide $i$ in cement; $m^{p}=$ the mass of Portland cement. The moles of alkali ions existing as sulfate are calculated as:

$n_{i}^{\text {sul }}=f_{i}^{\text {sul }} \cdot n_{i}^{T}$

where $n_{i}^{\text {sul }}=$ the moles of alkali ion $i$ in the sulfate form; $f_{i}^{\text {sul }}=$ the fraction of alkalis as sulfates. The procedure for determining $f_{i}^{s u l}$ is given by Taylor (Taylor, 1990).

In the case that the sulfate content in clinker is not known, estimated values for $f_{i}^{s u l}$ may be used, for example, $35 \%$ of $\mathrm{Na}_{2} \mathrm{O}$ and $70 \% \mathrm{~K}_{2} \mathrm{O}$ in the soluble sulfate form (Taylor, 1987). The amount of the other alkali ions bound in the clinker phases is calculated as:

$n_{i}^{c}=f_{i}^{c} \cdot n_{i}^{T}=\left(1-f_{i}^{s u l}\right) \cdot n_{i}^{T}$

where $f_{i}^{c}=$ the fraction of alkalis as solid solution in the clinker. The moles of alkali ions in each clinker 
Table 1. Fraction of alkali ions in individual clinker phases to the amount of non-sulfate alkali ions in clinker (Taylor, 1987).

\begin{tabular}{llllll}
\hline Alkali & Alite & Belite & Aluminate & Ferrite & Total \\
\hline $\mathrm{Na}_{2} \mathrm{O}$ & 0.44 & 0.17 & 0.36 & 0.03 & 1 \\
$\mathrm{~K}_{2} \mathrm{O}$ & 0.29 & 0.41 & 0.27 & 0.03 & 1 \\
\hline
\end{tabular}

phase $\left(\mathrm{C}_{3} \mathrm{~S}, \mathrm{C}_{2} \mathrm{~S}, \mathrm{C}_{3} \mathrm{~A}, \mathrm{C}_{4} \mathrm{AF}\right.$, etc.) are calculated by using $n_{i}^{c}$ and the distribution of alkali ions in clinker phases given in Table 1 (Taylor, 1987).

The amount of alkali ions which exist as nonsulfate and are released by the clinker hydration is calculated as:

$n_{i}^{r, c}=n_{i}^{T} \cdot \sum_{j=1}^{4}\left(f_{i, j} \cdot f_{i}^{c} \cdot \alpha_{j}\right)=n_{i}^{T} \cdot \sum_{j=1}^{4}\left[f_{i, j} \cdot\left(1-f_{i}^{s u l}\right) \cdot \alpha_{j}\right]$

where $i=$ the clinker phase (alite, belite, aluminate and ferrite); $f_{i, j}=$ the fraction of alkali ion $i$ (to the amount of non-sulfate ions in clinker) in the phase $j ; \alpha_{j}=$ the hydration degree of phase $j$. Hence, the total amount of alkali ions released by the cement hydration is:

$n_{i}^{r}=n_{i}^{s u l}+n_{i}^{r, c}=n_{i}^{T} \cdot\left\{f_{i}^{s u l}+\sum_{j=1}^{4}\left[f_{i, j} \cdot\left(1-f_{i}^{s u l}\right) \cdot \alpha_{j}\right]\right\}$

Obvious partition of alkali ions between the solid and aqueous phases takes place. The alkalis bound in the solid phases of cement are continuously released into the aqueous phase in the paste as the hydration proceeds. Parts of these alkali ions are absorbed by the hydration products (Taylor, 1987) and are immobilized, which are not available for the pore solution. The amount of alkali ions released by the cement hydration is accordingly divided into two parts: those in the solution and those bound in hydration products, yielding:

$n_{i}^{r}=n_{i}^{b}+n_{i}^{s}$

where $n_{i}^{b}=$ the amount of alkali ions bound in products; $n_{i}^{s}=\mathrm{s}$ the moles in the solution, which reads:

$n_{i}^{s}=C_{i} \cdot V_{w}$

where $C_{i}=$ the concentration of alkali ion $i(\mathrm{~mol} / \mathrm{L})$; $V_{w}=$ the volume of pore solution (L).

Taylor (1987) assumed that the amount of bound alkali ion is proportional to the concentration in the pore solution and the amount of hydration products, yielding:

$n_{i}^{b}=b a_{i} \cdot C_{i} \cdot F$ where $b a_{i}=$ the binding factor (L) of alkali $i ; F=$ fraction between the quantity of hydration products (dimensionless), which are able to take up alkali cations in the paste and that after complete hydration of cement.

Substituting Equation 8 and 7 into Equation 6, the alkali concentration in the pore solution is calculated as:

$C_{i}=\frac{n_{i}^{r}}{V_{w}+b a_{i} \cdot F}$

Note that the computations of Taylor (1987) are based on $100 \mathrm{~g}$ cement. In the Taylor's method, most of the parameters necessary for the computation are estimated using empirical equations. Thus, uncertainties are inevitable because those equations can hardly be valid for all cements under investigation. Furthermore, a constant value for $b a_{i}$ is used, implying a constant binding capacity of the hydration products. As stated by Taylor (1987), the assumption of this linear dependency had no theoretical basis. Experimental results by Hong \& Glasser (2002), Stade (1989) and computations in this study prove that the relation is not necessarily linear.

\subsection{Brouwers \& Van Eijk's method}

Brouwers \& Van Eijk (2003) further developed the method proposed by Taylor (1987). The concepts of alkali release and adsorption are taken over. Furthermore, the hydration degree of cement, the amount of alkali ions released by the cement hydration, the amount of C-S-H and volume of pore solution are computed from the outputs of one computer-based cement hydration model CEMHYD3D (Van Eijk, 2001). Uncertainties in the theory of Taylor (1987) induced by using some empirical equations are minimized by distinguishing the main hydration product $\mathrm{C}-\mathrm{S}-\mathrm{H}$ and all others. Hence, it is expected to give more accurate predictions over a wide range of cements. The authors took use of the results of the experiments by Hong \& Glasser (1999) to compute the C-S-H binding factors of alkalis and compared them to those used by Taylor (1987). Results from the experiments by Larbi et al. (1990) were used to validate the improved model. The model predictions agreed fairly well with the experimental results.

Brouwers \& Van Eijk (2003) proposed the amount of alkali ions bound in the products is calculated as

$n_{i}^{b}=R d_{i} \cdot C_{i} \cdot m_{C-S-H}$

where $m_{C-S-H}=$ the mass of C-S-H in the solids and $R d_{i}=$ the distribution ratio of alkali $i\left(\mathrm{Na}^{+}\right.$or $\left.\mathrm{K}^{+}\right)$, which is defined as (Hong \& Glasser, 1999):

$R d=\frac{\text { alkali in solid } \mathrm{C}-\mathrm{S}-\mathrm{H}}{\text { alkali concentration in solution }}(\mathrm{mL} / \mathrm{g})$ 
In this method, the alkali-binding capacity of C-S-H is assumed linearly proportional to the alkali concentrations in the solution because constant values of $R d_{i}$ are used. Only C-S-H in the products is considered as adsorbent because it is the most abundant phase in the products and is concluded to be the main binder of alkali ions (Brouwers \& Van Eijk, 2003). Substituting Equation 7 and 10 into Equation 6 yields:

$n_{i}^{r}=C_{i} \cdot V_{w}+R d_{i} \cdot C_{i} \cdot m_{C-S-H}$

Hence, the concentration of alkali ion is solved from Equation 12 as:

$$
C_{i}=\frac{n_{i}^{r}}{V_{w}+R d_{i} \cdot m_{C-S-H}}
$$

where $n_{i}^{r}=$ computed from Equation 5. The parameters in Equation 5 and $13\left(\alpha_{i}, m_{C-S-H}\right.$, and $\left.V_{w}\right)$ is computed by using the CEMHYD3D.

\section{NEW MODELS}

The alkali-binding capacity of hydration products (or the main product $\mathrm{C}-\mathrm{S}-\mathrm{H}$ ) is an essential factor in the methods proposed by Taylor (1987) and Brouwers \& Van Eijk (2003). In both methods, the alkali-binding factors are set to be constant based on the experimental results by using the synthetic $\mathrm{C}-\mathrm{S}-\mathrm{H}$, or constant values largely based on assumptions. However, a constant alkali-binding capacity of C-S-H is not supported by the experimental results of Hong \& Glasser (2002) and Stade (1989). In this study, new non-linear methods for determining the binding factors of C-S-H to $\mathrm{Na}^{+}$and $\mathrm{K}^{+}$in hydrating Portland cement pastes are proposed, which are derived from a large set of experimental results reported in literature.

\subsection{Alkali-binding capacity of $C-S-H$}

Stade (1989) studied the incorporation of alkali hydroxides in synthetic C-S-H and C-A-S-H gels. It is found that the amount of alkali hydroxide incorporated in C-S-H gels increases with decreasing $C / S$ ratio in it. The alkali-binding capacity of the Al-containing $\mathrm{C}-\mathrm{S}-\mathrm{H}$ gel is smaller than the Al-free gel at equal $C / S$ ratios. No obvious differences between the binding capacities for $\mathrm{Na}^{+}$and $\mathrm{K}^{+}$are observed in the experiments.

Hong \& Glasser $(1999,2002)$ studied the alkali binding in synthetic C-S-H and C-A-S-H gels as well. For the alumina-free $\mathrm{C}-\mathrm{S}-\mathrm{H}$, the alkali-binding capacity is found to increase linearly with increasing alkali concentrations in the solution. This linear relation is concluded from the approximately constant distribution ratios for C-S-H with fixed $C / S$ ratios. However, if alumina is incorporated into C-S-H, which takes place in real hydrating cement paste, the obtained C-A-S-H gels have obviously enhanced alkali-binding capacity, which is in contrast to the conclusion of Stade (1989). This enhancement is more obvious for C-A-S-H gels with low $C / S$ ratios. On the one hand, for all C-S-H and C-A-S-H gels, with increasing alkali concentrations in the solution, more alkali ions are held in the gels. On the other hand, the distribution ratio decreases with increasing alkali concentrations in the pore solution, which indicates that a linear relationship between the binding capacity and the alkali concentrations is questionable. Similar to the conclusion of Stade (1989), there is no significant difference between the alkali-binding capacity of C-S-H for $\mathrm{Na}^{+}$and $\mathrm{K}^{+}$.

A possible explanation for the different observations found in the experiments of Stade (1989) and Hong \& Glasser $(1999,2002)$ is the way of preparing the C-S-H gel. Stade (1989) made the C-S-H gel at $150^{\circ} \mathrm{C}$ by the autoclave reaction with $\mathrm{CaO}$ and silica, and at $80^{\circ} \mathrm{C}$ by precipitation from sodium silicate solutions with calcium chloride. Hong \& Glasser (1999, 2002) prepared the C-S-H gel by mixing $\mathrm{Ca}(\mathrm{OH})_{2}$ and a very reactive, high surface area silica gel in double-distilled, $\mathrm{CO}_{2}$-free water, sealed for 12 months at $20 \pm 2^{\circ} \mathrm{C}$ with regular agitation. The difference in the way of preparation and temperature may have a significant influence on the heterogeneity and structure of the C-S-H. The influence of different preparation temperature is already observed in the experiments of Stade (1989) as well.

Furthermore, the alkali concentrations used by Hong \& Glasser $(1999,2002)$ are between 0.015 to $0.3 \mathrm{mmol} / \mathrm{L}$. The alkali concentrations in the hydrating cement pastes under investigation are frequently outside this range because normally they are evaluated due to their high alkali oxide contents, which can potentially induce ASR in concrete. Therefore, higher concentrations of alkali ions in the pore solution are more relevant. Furthermore, the distribution ratio in real hydrating cement pastes can be significantly different from that of synthetic ones, which is of primary importance in modeling the pore solution composition.

\section{ALKALI-BINDING IN PRODUCTS}

Thirteen cement pastes using different cements or recipe tested in experiments are taken as basis. All the pastes are cured in sealed environment at various temperatures. Pore solutions are collected at the planned ages using the liquid compression method (Longuet et al., 1973). The oxide compositions of these cements are listed in Table 2 together with the recipe of the paste and the curing temperatures.

The hydration of these cement pastes are first simulated by using the computer model CEMHYD3D 
Table 2. Properties of the Portland cements and pastes used in experiments*.

\begin{tabular}{lrrrrlllll}
\hline Num & $\mathrm{C}_{3} \mathrm{~S}$ & $\mathrm{C}_{2} \mathrm{~S}$ & $\mathrm{C}_{3} \mathrm{~A}$ & $\mathrm{C}_{4} \mathrm{AF}$ & $\mathrm{SO}_{3}$ & $\mathrm{Na}_{2} \mathrm{O}$ & $\mathrm{K}_{2} \mathrm{O}$ & $w / c$ & $\mathrm{Temp}\left({ }^{\circ} \mathrm{C}\right)$ \\
\hline $1^{\mathrm{a}}$ & 56.8 & 19.7 & 6.9 & 11.3 & 3.25 & 0.43 & 1.23 & 0.42 & 23 \\
$2^{\mathrm{a}}$ & 70.0 & 8.8 & 7.4 & 11.3 & 3.0 & 0.2 & 0.47 & 0.42 & 23 \\
$3^{\mathrm{b}}$ & 54.5 & 21.3 & 10.9 & 9.2 & 3.1 & 0.21 & 0.82 & 0.4 & 22 \\
$4^{\mathrm{b}}$ & 54.5 & 21.3 & 10.9 & 9.2 & 3.35 & 0.21 & 0.82 & 0.45 & 22 \\
$5^{\mathrm{b}}$ & 54.5 & 21.3 & 10.9 & 9.2 & 2.7 & 0.21 & 0.82 & 0.56 & 22 \\
$6^{\mathrm{c}}$ & 55.0 & 15.0 & 7.9 & 8.1 & 0.88 & 0.08 & 1.12 & 0.5 & 20 \\
$7^{\mathrm{d}}$ & 58.0 & 16.0 & 7.0 & 12.0 & 0.91 & 0.16 & 0.51 & 0.35 & 22 \\
$8^{\mathrm{e}}$ & 63.8 & 12.4 & 11 & 8.8 & 3.21 & 0.14 & 0.95 & 0.5 & 20 \\
$9^{\mathrm{e}}$ & 69.8 & 6.8 & 9.6 & 9.7 & 2.59 & 0.19 & 1.22 & 0.5 & 20 \\
$10^{\mathrm{e}}$ & 65.8 & 15.2 & 8.7 & 10.2 & 3.21 & 0.64 & 0.78 & 0.5 & 20 \\
$11^{\mathrm{f}}$ & 64.3 & 17.3 & 8.5 & 9.9 & 3.1 & 0.32 & 0.6 & 0.4 & 23 \\
$12^{\mathrm{g}, \dagger}$ & 55.1 & 25.0 & 9.7 & 10.2 & 0.35 & 0.25 & 1.27 & 0.5 & 20 \\
$13^{\mathrm{g}, *}$ & 55.1 & 25.0 & 9.7 & 10.2 & 0.35 & 0.25 & 1.27 & 0.5 & 20
\end{tabular}

*. Mineral compositions are computed with the Bogue method.

a: taken from Bérubé et al. (2004); b: taken from Larbi et al. (1990); c: taken from Lothenbach \& Winnefeld (2006); d: taken from Rothstein et al. (2002); e: taken from Schäfer (2004); f: taken from Diamond (1981); g: taken from Longuet (1976);

$\dagger: 4.5 \mathrm{~m} / \mathrm{m} \%$ gypsum added;

\$: $8.6 \mathrm{~m} / \mathrm{m} \%$ gypsum added;

(Van Eijk, 2001). For cements whose fineness is unknown, a value of $380 \mathrm{~m}^{2} / \mathrm{kg}$ is assumed, corresponding approximately to CEM I $32.5 \mathrm{R}$ produced in the Netherlands. For facilitating the discussion, a similar concept as the "distribution ratio" is used, called "Molality" $(\mathrm{Ma})$ of alkalis in C-S-H. The molality physically represents the moles of alkali ions adsorbed by unit mass of the solid C-S-H gel. It is thus independent of the alkali concentrations in the pore solution and allows deriving the non-linear binding relationship. According to its definition, the molality is calculated as:

$M a=\frac{n_{i}^{b}}{m_{C-S-H}}(\mathrm{mmol} / \mathrm{g})$

Substituting Equation 14 and 7 into Equation 6 gives:

$M a_{i}=\frac{n_{i}^{r}-C_{i} \cdot V_{w}}{m_{C-S-H}}$

If the molality is known, the alkali concentration is calculated as:

$C_{i}=\frac{n_{i}^{r}-M a \cdot m_{C-S-H}}{V_{w}}$

Similarly, the distribution ratio is calculated as:

$R d_{i}=\frac{n_{i}^{r}-C_{i} \cdot V_{w}}{C_{i} \cdot m_{C-S-H}}$
The parameters $n_{i}^{r}, V_{w}$ and $m_{C-S-H}$ in Eqs (16) and (18) are obtained with the CEMHYD3D. Therefore, the $M a$ and $R d_{i}$ for alkalis in C-S-H can now be computed. The calculated $M a$ for $\mathrm{Na}^{+}$and $\mathrm{K}^{+}$are plotted as a function of the alkali concentration in Figure 1 and the calculated $R d_{i}$ in Figure 2.

It can be seen in Figure $2 \mathrm{a}$ that there is a linear relationship between the molality of $\mathrm{Na}^{+}$in $\mathrm{C}-\mathrm{S}-\mathrm{H}$ and its concentration, implying a linear binding capacity of C-S-H for $\mathrm{Na}^{+}$. This linear binding model is in agreement with the hypothesis by Taylor (1987) and Brouwers \& Van Eijk (2003).

However, for the molality of $\mathrm{K}^{+}$in C-S-H (Fig. 2b), this linear relationship cannot be discerned. On the contrary, when observing the distribution ratio for $\mathrm{K}^{+}$ (Fig. 3b), it can be seen that it decreases with increasing $\mathrm{K}^{+}$concentrations, indicating a non-linear binding of $\mathrm{C}-\mathrm{S}-\mathrm{H}$ to $\mathrm{K}^{+}$ions. Most likely a non-linear binding model should be applied here.

A linear regression analysis for the linear relation in Figure 2a gives:

$M a_{N}=0.45 C_{i} \quad(\mathrm{mg} / \mathrm{g}) ; \quad R d_{N}=0.45(\mathrm{~mL} / \mathrm{g})$

The non-linear relation in Figure $2 \mathrm{~b}$ can be fitted with:

$R d_{K}=0.20 C_{i}^{-0.76}(\mathrm{~mL} / \mathrm{g})$

The Equation 19 complies with the Freundlich isotherm, which is widely used to describe the adsorption of solutes in solution by solid phases. It can be seen in Figure 2 that the distribution ratios of $\mathrm{Na}^{+}$ 


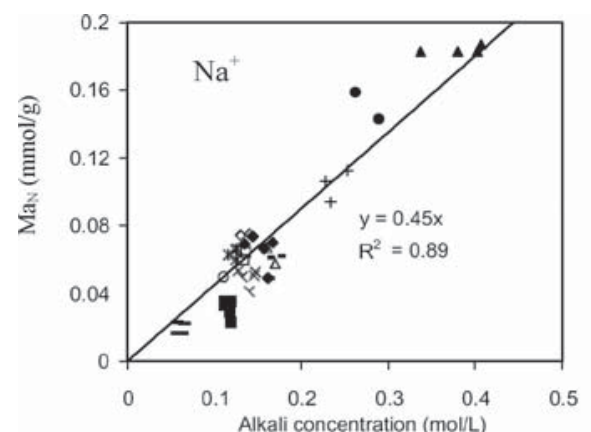

(a)

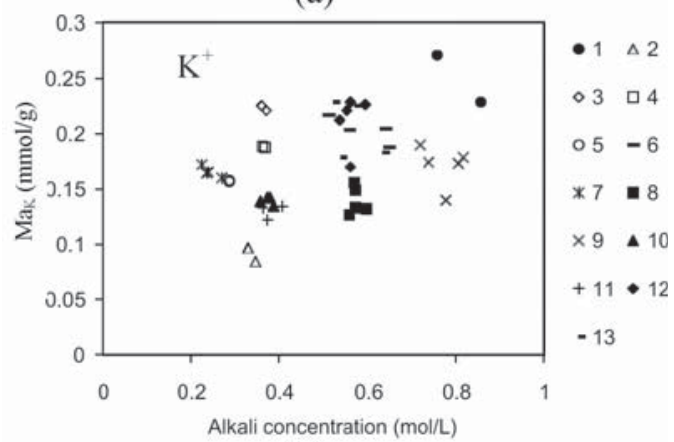

(b)

Figure 1. Molality of alkalis versus concentrations in solution calculated with Equation 16. Numbers in the legend correspond to the cement numbers in Table 2.

and $\mathrm{K}^{+}$for hydrating Portland cement paste have similar values. A detailed comparison shows that for low alkali concentrations (about $0-400 \mathrm{mmol} / \mathrm{L}$ ) the distribution ratio of $\mathrm{K}^{+}$is slightly higher than that of $\mathrm{Na}^{+}$. With increasing alkali concentrations, the later gradually surpasses the former.

The constant values of $R d_{N}$ and $R d_{k}$ used by Brouwers \& Van Eijk (2003) and those derived from the study of Taylor (1987) are included in Figure 2 as well. It can be seen that the values of $R d$ in these two studies (Brouwers \& Van Eijk, 2003; Taylor, 1987) are in line with the calculations in this study. The used values of $R d_{N}$ are the same in the two studies, because (a) the linear relation used are indeed valid for $\mathrm{Na}^{+}$ and (b) the used values are very close to the predictions in this study. However, two remarkably different values are used for $R d_{K}$ because of the differences in the concentrations of $\mathrm{K}^{+}$measured in the different experiments. The $R d_{K}$ value used by Taylor (1987) $0.25 \mathrm{~mL} / \mathrm{g}$ - is valid for the high concentrations (e.g. $400-600 \mathrm{mmol} / \mathrm{L}$ in Figure 1 of Taylor (1987), while the value used by Brouwers \& Van Eijk (2003) $0.38 \mathrm{~mL} / \mathrm{g}$ - is valid for relative lower concentrations $(370 \mathrm{mmol} / \mathrm{L})$. Therefore, for low $\mathrm{K}^{+}$concentrations,

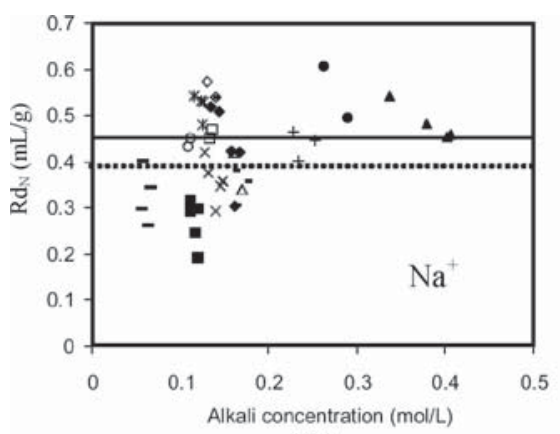

(a)

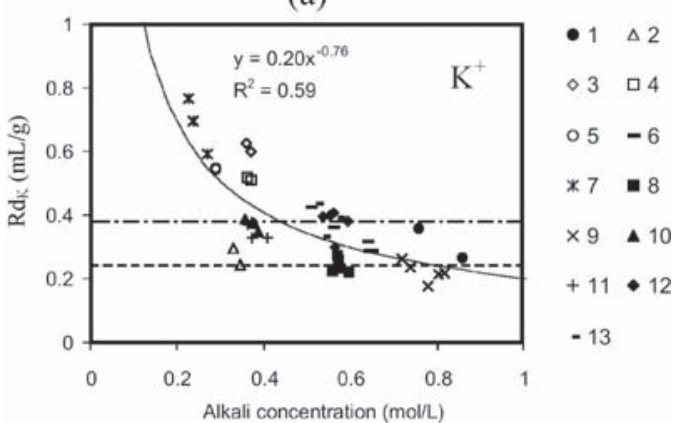

(b)

Figure 2. Distribution ratio of alkalis versus concentration in solution calculated with Equation 18. Numbers correspond to the cement numbers in Table 3. "-": values for $\mathrm{Na}^{+}$used by Taylor (1987) and Brouwers \& Van Eijk (2003); "-.....". values for $\mathrm{K}^{+}$used by Brouwers \& Van Eijk (2003); “---". values for $\mathrm{K}^{+}$used by Taylor (1987), “__”: values suggested in the present work.

the predictions with Taylor's value are obviously higher than the measurements.

Furthermore, it is illustrated in this figure that C$\mathrm{S}-\mathrm{H}$ in hydrating cement paste can bind more $\mathrm{K}^{+}$than $\mathrm{Na}^{+}$, due to the generally lower concentration of $\mathrm{Na}^{+}$ than that of $\mathrm{K}^{+}$. Therefore, it is essential to distinguish the alkali types in the cement while evaluating the alkali-binding capability of C-S-H in hydrating cement paste. If the cement is low in both $\mathrm{Na}_{2} \mathrm{O}$ and $\mathrm{K}_{2} \mathrm{O}$, relatively more $\mathrm{K}^{+}$is immobilized in the solid phases. If the levels increase for both alkalis, the binding capability of $\mathrm{Na}^{+}$is much more enhanced than that of $\mathrm{K}^{+}$, and surpasses the latter at a certain level.

\section{VALIDATIONS OF THE NEW MODEL}

Taylor (1987) determined the value of binding factor from measurements in nine laboratories and validated it with four batches of samples in these laboratories. A similar idea is used here as well, by validating the new method with four of the 13 recipes in Table 2 . 
These four recipes cover cements from different literatures and with varying alkali contents. The proposed method for determining $R d$ value of $\mathrm{Na}^{+}$and $\mathrm{K}^{+}$in hydrating cement paste (Equation 19 and 20) is used to predict the alkali concentrations in the pore solution. The hydration of these four cements is simulated with the CEMHYD3D. The results are included in Figure 3, together with the experimental measurements with Cement 4-7.

It can be seen that concentrations are correctly predicted for both $\mathrm{Na}^{+}$and $\mathrm{K}^{+}$, to a better extent for $\mathrm{Na}^{+}$. Therefore, it can be concluded that the proposed method can accurately predict the alkali concentrations in a wide range. The method takes different factors into account, for example, the mineral composition of cement, its fineness, the $w / c$ ratio, the alkali contents in cement, and the curing temperature. For modeling the $\mathrm{Na}^{+}$concentration, the linear model by Taylor (1987) and Brouwers \& Van Eijk (2003) is indeed valid, and for modeling the $\mathrm{K}^{+}$concentration, the non-linear method given in Equation 20 should be followed.

\section{CONCLUSIONS}

A new method is proposed in this study for determining the distribution ratio of alkalis in hydrating Portland cement pastes. It is derived from experimental results taking use of a large number of cement pastes selected from literature. The adsorption of alkali ions by the solid product C-S-H in hydrating Portland cement pastes complies with the Freundlich isotherm. The higher alkali concentrations, the more alkali ions are bound in the solid products. The linear binding model used by Taylor (1987) and Brouwers \& Van Eijk (2003) is valid for $\mathrm{Na}^{+}$, but a non-linear method should be followed for $\mathrm{K}^{+}$

A new computed-based model is proposed as well, which can precisely predict the alkali concentrations in the pore solution of hydrating Portland cement paste. Together with computer modeling, the models established in this study can be used to investigate the long-term changes of alkali concentrations in the pore solution.

\section{ACKNOWLEDGEMENT}

The authors wish to thank the following institutions for their financial support of the research of Dr. Wei Chen during his stay at University of Twente: Dr. ir. Cornelis Lely Foundation, Delta Marine Consultants, Betoncentrale Twenthe, Rokramix, Dutch Ministry of Infrastructure, SenterNovem Soil+, Jaartsveld Groen en Milieu.
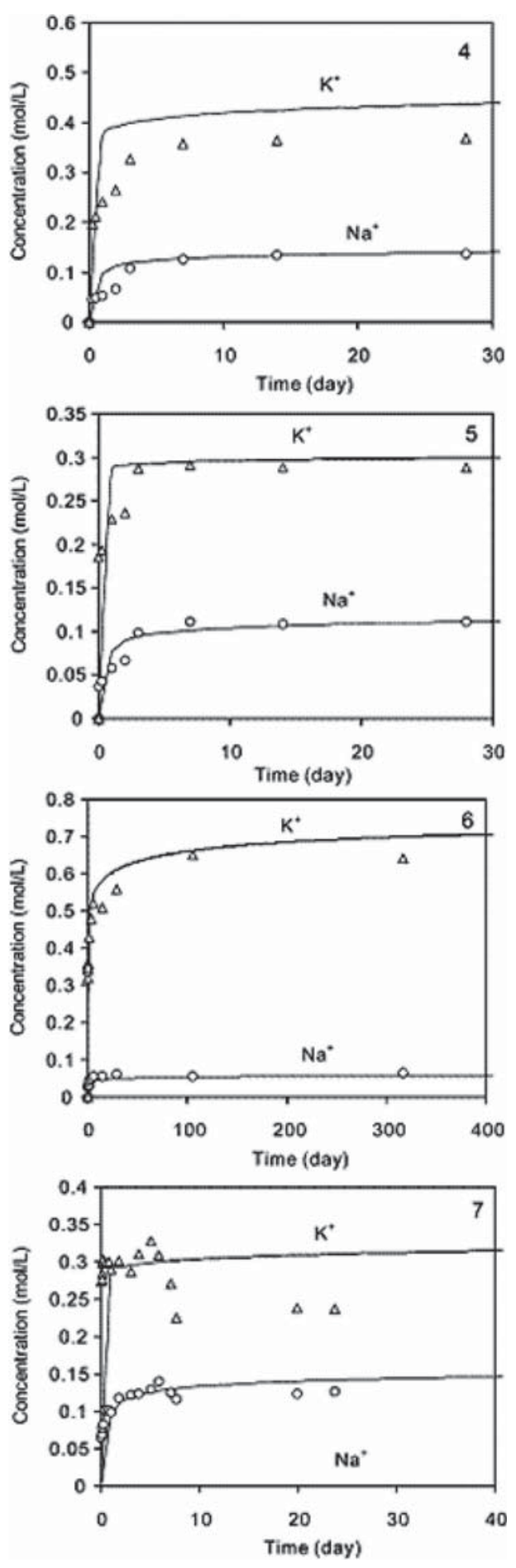

Figure 3. Predicted and measured concentration of alkali ion in the pore solution for Cement 4-7 from Table 2. 


\section{REFERENCES}

Anstice, D. Page, C.L. Page, M. 2004. The pore solution phase of carbonated cement pastes. Cement and Concrete Research 35(2): 377-388.

Bérubé, M.A. Tremblay, C. Fournier, B. Thomas, M.D. Stokes, D.B. 2004. Influence of lithium-based products proposed for counteracting ASR on the chemistry of pore solution and cement hydrates. Cement and Concrete Research 34 (9): 1645-1660.

Brouwers, H.J.H. Van Eijk, R.J. 2003. Alkali concentrations of pore solution in hydrating OPC. Cement and Concrete Research 33: 191-196.

Dehwah, H. Malslehuddin, M. Austin, S. 2002. Effect of cement alkalinity on pore solution chemistry and chlorideinduced reinforcement corrosion. ACI Materials Journal 99 (3): 227-233.

Diamond, S. 1981. Effect of two Danish fly ashes on alkali contents of pore solutions of cement-flyash pastes. Cement and Concrete Research 11: 383-394.

Glasser, F.P. 2003. The pore fluid in Portland cement: its composition and role. In: Proc. 11th ICCC: 341-352. Durban, South Africa.

Hong, S.Y. Glasser, F.P. 1999. Alkali binding in cemen pastes: Part I, The C-S-H phase. Cement and Concrete Research 29: 1893-1903.

Hong, S.Y. Glasser, F.P. 2002. Alkali sorption by C-S-H and C-A-S-H gels: Part II. Role of alumina. Cement and Concrete Research 32: 1101-1111.

Larbi, J.A. Fraay, A.L. A. Bijen, J.M. 1990. The chemistry of the pore fluid of silica fume-blended cement systems. Cement and Concrete Research 20: 506-516.

Longuet, P. 1976. La protection des armatures dans le béton armé élaboré avec des ciments de laitier. Silicates Industriels 7/8: 321-328.
Longuet, P. Burglen, L. Zelwer, A. 1973. The liquid phase of hydrated cement. Rev. Mater. Constr. 676: 35-41.

Lothenbach, B. Winnefeld, F. 2006. Thermodynamic modelling of the hydration of Portland cement. Cement and Concrete Research 36(2): 209-226.

Page, C.L.Vennesland, O. 1983. Pore solution composition and chloride binding capacity of silica-fume cement pastes. Materials and Structures 16(91): 19-25.

Pollitt, H. Brown, A.W. 1968. The distribution of alkalis in Portland cement clinker. In: Proc. 5th ISCC: 322-333. Tokyo.

Rothstein, D. Thomas, J.J. Christensen, B.J. Jennings, H.M. 2002. Solubility behavior of Ca-, S-, Al-, and Si-bearing solid phases in Portland cement pore solutions as a function of hydration time. Cement and Concrete Research 32: 1663-1671.

Schäfer, E. 2004. Einfluss der Reaktionen verschiedener Zementbestandteile auf den alkalihaushalt der Porenlösung des Zementsteins. Ph.D. thesis, Clausthal University of Technology, Clausthal-Zellerfeld, Germany. Schäfer, E. Meng, B. 2001. Influence of cement and additions on the quantity of alkalis available for an alkali-silica reaction. Tech. rep. VDZ, Düsseldorf, Germany.

Stade, H. 1989. On the reaction of C-S-H(di, poly) with alkali hydroxides. Cement and Concrete Research 19(5): 802-810.

Taylor, H.F.W. 1987. A method for predicting alkali ion concentrations in cement pore solutions. Advances in Cement Research 1(1): 5-16.

Taylor, H.F.W. 1990. Cement chemistry (1st Ed.), London: Academic press

Van Eijk, R. J. 2001. Hydration of cement mixtures containing contaminants. Ph.D. thesis, University of Twente, Enschede. 